\title{
Digital Cultural Heritage and Social Sustainability
}

\author{
Chern Li Liew
}

Gobinda Chowdhury
Victoria University of Wellington, New Zealand

Corresponding Author.

ChernLi.Liew@vuw.ac.nz

Northumbria University, United Kingdom

gobinda.chowdhury@northumbria.ac.uk

This research investigated factors that were perceived to contribute to the social sustainability of cultural heritage information services. Semistructured interviews were conducted with sixteen users, guided by three broad questions: 1. What factors they consider are important for DCH services to be socially sustainable or to achieve social sustainability? 2. What indicators they perceive from current DCH services that suggest social sustainability? 3. What they believe are the main challenges for DCH services to achieve or maintain social sustainability?

Social sustainability of DCH information services was associated with: strategy and policy, advocacy and community engagement, equity, cultural sensitivity and literacy, assessment and evaluation.

\section{Introduction}

Cultural heritage contents come in different forms. They may be tangible, movable objects such as paintings, sculptures, textiles and musical instruments, or immovable objects such as buildings and monuments. They could also be intangibles or immaterial items such as folk tales and songs, poetries and dance (UNESCO, 2008; Cane and Conagham, 2009). Research and development activities in digital information over the past two decades have given rise to a number of digital libraries and digital archives providing access to cultural heritage information services such as the from the US Library of Congress American Memory and the Europeana digital library, an initiative involving a large number of memory institutions and

Liew, C.L., Chowdury, G. (2016). Digital cultural heritage and social sustainability. The Journal of Community Informatics, 12(3), 173-196.

Date submitted: 2015-10-21. Date accepted: 2016-09-18.

Copyright (C), 2016 (the authors as stated). Licensed under the Creative Commons AttributionNonCommercial-ShareAlike 2.5. Available at: www.ci-journal.net/index.php/ciej/article/view/1278. 
industries across Europe (Nicholas, Clark, Rowlands and Jamali, 2013). The European Commission has a long commitment to safeguarding and enhancing Europe's cultural heritage as an important resource for promoting economic growth, employment and social cohesion (European Commission, 2014).

Tait et al (2013) observe that digital cultural heritage (DCH) information services vary according to the actors which manage them, their spatial reach, their content and the software technologies which underpin them. Liew (2010) discusses the importance of addressing issues around cultural divide and social exclusion. Innocenti (2015) recommends that a framework is needed to support and monitor cultural heritage information services which includes defining agreed performance indicators and success parameters. Many of the issues and recommendations put forward and documented in recent literature point towards the need to address issues around the sustainability of cultural heritage information services.

The main purpose of the research reported in this paper was to identify factors that were perceived to contribute to the social sustainability of cultural heritage information services from the perspectives of users. The overall aim was to identify social sustainability issues that could be addressed through policy, design, management and delivery of cultural heritage information services. In the next section, we discuss the importance of social sustainability in the context of DCH information services. The research design of this study is then outlined before we present the interview findings. The paper concludes with a highlight of the main findings and an indication of the way forward.

\section{Social sustainability and Digital cultural heritage information services}

The term sustainability has become a major focus of government, businesses and industries. There are three pillars of sustainability, viz. economic sustainability, social sustainability and environmental sustainability. In the context of a digital information service, Chowdhury (2014) states that:

- economic sustainability can be achieved by building a sustainable business model, 'for profit' or 'not-for-profit' depending on the service provider and their characteristics as well as taking measures for reduction of cost in the creation, distribution and access to information; and taking measures for reduction in the user time and efforts for discovery, access and use of information

- the target for social sustainability is to ensure easy and equitable access to information; (a) by increasing the accessibility and usability relevant to the user context, culture, etc.

- the target for environmental sustainability is to ensure reductions in the environmental impact by taking measures to reduce the greenhouse gas emissions and carbon footprint of the information system.

Social sustainability may be defined as the maintenance and improvement of well-being of the current and future generations of people (Mak and Peacock, 2011). Many research projects have identified indicators for different aspects of sustainable development (Adelle and Pallemaerts, 2009). Reviews of different initiatives that attempted to define indicators of sustainability show that there have been as many as 255 indicators for sustainable development (Hutchins and Sutherland, 2008; Hutchins, Gierke and Sutherland, 2009). 
Information services are designed to provide access to information as a shared resource. The proliferation of the Web, social networking services, and mobile technologies has significantly facilitated access to knowledge in a number of ways. These new technologies could be used to promote the social sustainability of information services. However, it may be argued that these technologies could also create several inequalities. Many researchers have discussed different socio-political implications of the modern ICT, the Web and mobile technologies in the context of information systems and services (Feather, 2013; Chowdhury, 2014).

In recent years, many cultural heritage information services have been exploring the use of Web 2.0 and social media to develop and to promote user-centred content creation and access. Some view these as opportunities to engage with their users and hence, to improve their social sustainability. Deodato (2014) comments that Web 2.0 has been instrumental in promoting a participatory culture - one that focuses on facilitating interaction and the creation of content by users rather than the consumption of content created or compiled by experts, thereby offering a model of socially responsible librarianship based on relinquishing some power to users and providing them with the tools to participate more fully in the construction of knowledge. Other researchers have cautioned however that not all cultural heritage institutions that have implemented Web 2.0 have fully embraced a participatory culture (Liew, 2014).

Ideally, a socially sustainable digital information service should be ubiquitous, i.e. it should be embedded in the work and culture of people in such a way that they get access to the information that is relevant to their work and activities even without having to actively ask for it (Chowdhury, 2013; 2014). Thus the design of a socially sustainable digital information service should be based primarily on the user's context, and the aim should be to provide information to the users that are not only context-specific but are also value-added and therefore appropriate for accomplishing a specific task or activity.

Much of the literature on social sustainability appears to be examination of the topic from a project or an institution's point of view. Social sustainability is associated with a number of factors, such as the design, accessibility and usability of information systems and services; and information behaviour and literacy of users. Other social sustainability issues are related to copyright and digital rights management; international, national and local or institutional policies and practices with regard to information products and services; and some specific cultural issues, for example those that are associated with indigenous cultural heritage information (Chowdhury 2015; Liew, 2012; Francis and Liew, 2009).

\section{Research Design}

Semi-structured interviews (face-to-face; Skype; email) with sixteen users of three DCH projects were conducted. The three DCH information services were:

- New Zealand Electronic Text Collection (NZETC) (http://nzetc.victoria.ac.nz)- This freely accessible collection comprises both digitized and born digital content of historical works of significant New Zealand and Pacific Island texts and other materials. The collection supports the teaching, learning and research at Victoria University Wellington, although access to this collection is not limited to the university users only. 
- Kete Horowhenua (KH) (http://horowhenua.kete.net.nz) - This is a community-built digital library of arts, cultural and heritage resources for and about Horowhenua, New Zealand.

- New Zealand History Online (NZHO) (http://www.nzhistory.net.nz) - The collection features information and resources from within the History Group of the New Zealand Ministry for Culture and Heritage, covering three main theme: Culture and society, Politics and government and War and society.

The three projects were chosen as they were amongst the most commonly known DCH information services in New Zealand,.

A 'questionnaire' was emailed to each participant in preparation for the interviews two weeks in advance (Please see Appendix 1). Three readings on social sustainability were suggested to participants in order to help them prepare for the interviews. We acknowledge that these readings might have oriented or influenced participants' responses to the questions; nevertheless, we thought this was necessary because social sustainability is not a very commonly understood concept, and often definition and scope of the concept vary. Three broad questions that guided the semi-structured interviews were:

- What factors they consider are important for DCH services to be socially sustainable or to achieve social sustainability?

- What indicators they perceive from current DCH services that suggest social sustainability?

- What they believe are the main challenges for DCH services to achieve or maintain social sustainability?

The face-to-face and Skype interviews which lasted between approximately 45 and 90 minutes in length were conducted on a conversational basis as much as possible, with interviewees encouraged to expand upon the main questions and to explain relevant issues as they experienced and perceived them.

All participation was voluntary. The first three interviewees were students in a course in an Information Studies programme who volunteered to take part in the study. Each of these students also held employment at a local memory institution. A snowball sampling was then used - each of the interviewees suggested potential participants based on their knowledge of other users of the DCH service they had used. The criteria for participation were that the interviewee must have used at least one of the DCH services for personal or work-related goals, and/or for education purposes, and that they were familiar with most of the features and functionality of the DCH sites. Persons who worked for or had been employed for any of the three DCH services were excluded from the study. Table 1 provides the brief profile of the participants. To protect the identity of the participants, age is reported as range. 
Table I: Brief profile of the study participants

\begin{tabular}{|c|c|c|c|}
\hline $\begin{array}{c}\text { Interviewe } \\
\mathbf{e}\end{array}$ & Gender/Age & Background & $\mathrm{DCH}(\mathrm{s})$ used; Purpose(s) of use \\
\hline $\mathrm{P} 1$ & $\begin{array}{l}\text { F e m a } 1 \text { e / } \\
56-60\end{array}$ & Work part-time at a small museum & $\begin{array}{l}\text { NZHO; research (work) and personal } \\
\text { interests }\end{array}$ \\
\hline $\mathrm{P} 2$ & $\begin{array}{l}\mathrm{F} \text { e } \mathrm{m} \text { a } 1 \text { e / } \\
31-35\end{array}$ & Part-time community archivist & $\begin{array}{l}\text { KH; personal interests } \\
\text { NZETC; education }\end{array}$ \\
\hline P3 & $\begin{array}{l}\mathrm{F} \text { e } \mathrm{m} \text { a } 1 \text { e / } \\
41-45\end{array}$ & $\begin{array}{l}\text { Work full-time at a university library; } \\
\text { deal with archival materials }\end{array}$ & $\begin{array}{l}\text { NZETC; research (work) and personal } \\
\text { interests } \\
\text { NZHO; research (work) }\end{array}$ \\
\hline P4 & $\begin{array}{l}\mathrm{F} \text { e } \mathrm{m} \text { a } 1 \text { e / } \\
26-30\end{array}$ & Part-time library assistant & $\mathrm{KH}$; personal interests \\
\hline P5 & Male/ 41-45 & Team leader at a district library & $\begin{array}{l}\text { NZHO and NZETC; research (work) } \\
\text { and personal interests }\end{array}$ \\
\hline P6 & Male/ 51-55 & Unemployed & NZHO and NZETC; personal interests \\
\hline $\mathrm{P} 7$ & $\begin{array}{l}\mathrm{F} \text { e } \mathrm{m} \text { a } 1 \text { e } / \\
41-45\end{array}$ & Research scientist at a state institution & $\begin{array}{l}\text { NZHO and NZETC; research (work) } \\
\text { and personal interests }\end{array}$ \\
\hline P8 & Male/ 31-35 & Volunteer at a community library & $\mathrm{KH}$; personal interests \\
\hline P9 & Male/ 26-30 & Work full-time at a university library & $\mathrm{KH}$; personal interests \\
\hline $\mathrm{P} 10$ & $\begin{array}{l}\text { F e m a } 1 \text { e / } \\
41-45\end{array}$ & $\begin{array}{l}\text { Resource discovery manager at a } \\
\text { university library }\end{array}$ & $\begin{array}{l}\text { NZETC and NZHO; education, research } \\
\text { (work) and personal interests }\end{array}$ \\
\hline $\mathrm{P} 11$ & $\begin{array}{l}\mathrm{F} \text { e } \mathrm{m} \text { a } 1 \mathrm{e} / \\
31-35\end{array}$ & Part-time library assistant & $\mathrm{KH}$; personal interests \\
\hline $\mathrm{P} 12$ & Male/ 36-40 & Volunteer at a community archive & $\begin{array}{l}\text { NZETC; education } \\
\mathrm{KH} \text {; personal interests }\end{array}$ \\
\hline $\mathrm{P} 13$ & $\begin{array}{l}\text { F e m a } 1 \text { e } / \\
41-45\end{array}$ & Institutional repository administrator & NZETC and KH; personal interests \\
\hline $\mathrm{P} 14$ & $\begin{array}{l}\text { F e m a } 1 \text { e / } \\
26-30\end{array}$ & Volunteer at community archive & $\mathrm{KH}$; personal interests \\
\hline $\mathrm{P} 15$ & Male/ 46-50 & $\begin{array}{l}\text { Work full-time at a university library; } \\
\text { genealogist }\end{array}$ & $\mathrm{KH}$; personal interests \\
\hline $\mathrm{P} 16$ & $\begin{array}{l}\text { F e m a } 1 \text { e / } \\
31-35\end{array}$ & Volunteer at a community library & $\begin{array}{l}\text { NZHO and NZETC; research (work) } \\
\text { and personal interests }\end{array}$ \\
\hline
\end{tabular}

We acknowledge that most of the participants have been involved to different extent, in cultural heritage projects or institutions. Hence, the study sample may not be a complete representation of the population of DCH users in general. Nevertheless, the richness and the depth of the data collected should provide worthwhile insights that could be useful in the broader context. 


\section{Findings}

What factors they consider are important for DCH services to be socially sustainable or to achieve social sustainability

The interviewees were asked about factors they considered were important for a DCH service to be socially sustainable or to achieve social sustainability. Their responses were manually analysed and four main themes emerged through the data: the importance of (i) strategy and policy, (ii) advocacy and community engagement, (iii) equity, cultural sensitivity and literacy and (iv) assessment and evaluation. Important concepts and themes appearing through the respondent's comments were highlighted (in bold) in order to facilitate data analysis and discussions.

\section{Strategy and Policy}

The perceived benefits of having relevant strategies and policies in place were linked to sending a clear message about an institution's stance on social sustainability and to meeting current and future needs of users and communities:

"Project plans that are informed by institutional social sustainability policies and allocate sufficient resources for related activities play an important role in aligning digital heritage projects with the current and future needs of primary users and the wider community." (P2)

"An important question that needs to be answered is does the organisation's policy address social sustainability as an issue? If there is no documented evidence of either the organisation or the digital collection unit taking social sustainability issues seriously, it is doubtful that the collection or service will be socially sustainable." (P3)

"Institutions must work to promote their digital arms as core components of a wider mandate fundamental to the overall sustainable and relevance of the parent institution itself. This should be reflected in the strategic plan." (P4)

Two participants also emphasized the importance of addressing this not only at an institutional level, but in a wider context:

"In my opinion, addressing social sustainability at a sector-wide and institutionwide level, through advocacy, strategy and policy provides a foundation for creating value for end users ... a strategic plan should be grounded in an understanding of the benefits of participatory practice, user engagement and iterative approaches." (P1)

One of the participants, a team leader at a district library discussed strategy and planning as related to risk management, as well as to the importance of maintaining and demonstrating continuing relevance of a DCH service:

"For cultural heritage institutions with a vision of sustainability, sustainability indicators could be considered in the context of their internal and external environments in order to inform strategic and operational planning related to their 
digital collections. An outcome of such formal planning processes would ideally be the articulation of goals and objectives which would help to focus the activities of the organisation at a fundamental level on the creation and on-going management of socially sustainable digital collections. Cultivating organisational competencies in this manner would allow institutions to fully exploit opportunities in the cultural heritage sector, to manage risk effectively and to be of continuing relevance and benefit to society." (P5)

The importance of taking into account the appropriate legal framework, including rights and use management, was also raised by an interviewee who worked at a university library:

"Important legal aspects include copyright compliance and explicit copyright procedures and it is very important to get this right, as digital content that ignores this cannot be sustained as it cannot be used, reused and shared legally by users. "(P9)

One interviewee, who was an institutional repository administrator, highlighted the particular attention needed for dealing with resources of cultural significance and political sensitivity:

"Memory institutions should create policies specific to their culturally significant digitised resources, laying out clear conditions of use and what actions by both the institution and its users will revoke the consent of the resources owners. ...The institution must do everything in its power to discourage its users from using its collection unethically." (P13)

\section{Advocacy and Community engagement}

Advocacy, building and maintaining relationships with users and the wider community is perceived by a number of interviewees to be an important step towards social sustainability. Empowering users and providing them a sense of ownership was also perceived to be an important aspect:

"Post-launch community education and resource management play key roles in the social sustainability of digital collections and services. Effective community management include sustaining relationships with existing users and encouraging a sense of ownership among stakeholders." (P2)

"Keeping the relationship between users and the digital information services relies on each party viewing the link as reciprocal and supportive of a long-term relationship. A digital information service must be seen to be both accommodating and responsive to the needs of its audience ... The relationship between the institution and the users can result in the institution correctly identifying the needs of its users ... This responsibility makes the user community aware of the institution's appreciation and the overall commitment to the dissemination of relevant cultural heritage information." (P4)

Two interviewees raised the issue of cultural diversities. Both of them, who worked at a university library, believed a socially sustainable DCH information service should ensure equality of representation of the different cultures of the communities it served: 
"Social sustainability relates to the ability of the project to build and empower the community it serves, to be relevant within that community and to negotiate cultural diversities." (P9)

"A sustainable collection that socially fulfills a community's needs is one that promotes and encourages equitable, collaborative and open participation with social awareness, social inclusiveness embedded in its work practices and organisational issues. The way a collection is designed should incorporate each of these aspects. Communities require a collection that is freely available and is appealing. It means engaging the community and has a sense of identity to help bring positive change to the community. A collection must have cultural aspects associated with it for a community to effectively engage with the content. A socially acceptable collection is one that allows people to work together for a stronger community and creates a sense of achievement together." (P10)

"For cultural heritage, communities must share a clear understanding that mutual trust and support is gained through making relationships which enhance content through digitisation. This means a sustainable system needs to have clear relevance, accessibility and visibility to understand the organisation and the community's needs. For a digital collection to be accepted and used in a community it must have significant input by different groups. A community that is engaged with the social and cultural aspects of a collection will positively change and create an empowerment with the material used. The design should be built around the community, identity, social structures and work practices to help drive and preserve the content long term.” (P10)

Consultation and engagement with the communities concerned were also mentioned by two interviewees who worked at community archives, as key steps towards achieving social sustainability:

"The memory institution should proactively facilitate integration of digital resources into teaching, learning, research and community activities, with a view to supporting community engagement and empowerment. Communities should be encouraged to share their knowledge and personal collections in collaborative effort to enhance memory collections." (P2)

"Community consultation and engagement is an important indicator of social sustainability. Community consultation can be used to identify needs and to provide better services by addressing the issues which have the most value and impact on the users." (P14)

Also noteworthy were the points made about the importance of developing trust, a sense of identity and ownership and encouraging collaboration and participation.

The use of social media and Web 2.0 to facilitate these was mentioned by other interviewees:

"I've seen how the integration of social networks and Web 2.0 technologies gives users the means to communicate with a service. The number of Web 2.0 technologies 
integrated into a digital collection is a potential indicator for how sustainable the collection might be, since this integration will allow users to interact with the collection in ways that will keep it updated and active and for users to let the institution know how the collection can stay valuable." (P7)

"Digital collections aligned to organisational aims and strong user communities are essential for social sustainability. Social media can use used to encourage user engagement and actively foster social inclusiveness." (P8)

\section{Equity, Cultural sensitivity and Literacy}

The importance of equity was raised by most of the interviewees. Most of them commented on the need to represent the diversity of cultures, languages and literacy skills present in their projects / sites / services. Accessibility and usability were also perceived to be important concerns. As there were quite a few comments with regard to these, the relevant data extracts are presented in Appendix 2.

One interviewee also made the point about embedding socially sustainable practice in organisational culture:

"Issues related to equity of access to such as Internet infrastructure, Internet access costs and digital literacy are generally addressed at a national and sector level. It is also important to acknowledge the importance of educating and supporting staff in a way that embeds socially sustainable practices in their organisational culture. This provides a foundation for institutional policy that requires all digital projects to identify potential users, involve users and other stakeholders as well as potential users in the planning and development of digital collections and resources." (P1)

Another interviewee commented how the costs of investing in DCH service could be high and hence, the importance of thinking about sustainability at the start:

"In any consideration of digital collections, time must be given to consider how the collection may be sustained over the long term. If a collection cannot be sustainable there is often very little point in investing what can be a significant amount of time and money and most importantly, the resources themselves and the effort in curating them." (P9)

A number of them also linked equity of access to technology compatibility:

"It is important to assess how easy it is for a broad cross-section of users to access a digital collection. Economic considerations should be taken into account because of the major effect they have on social equity. Similarly, the number of open source formats available for content downloads is another indicator that could be used. The infrastructure of the digital collection might also present barriers to use, so assessing the proportion of the collection's interface that is compatible with different technologies will determine what percentage of users will be shut out from accessing the collection. The number of accessibility measures and technologies provided for browsing the collection for those with impairment should also be considered." (P7) 
"To promote equity of access in these contexts, a socially sustainable digital heritage provider will implement solutions that are accessible to mobile devices. Making content available to mobile devices presents a tremendous opportunity for collections to be made available to a large section of the community." (P12)

"Also included in the cost of accessing a digital development is the means by which the user connects to the collection. Users should not have to purchase expensive software to engage with the collection, nor should the system requirements for the electronic devices they use for access be unreasonable. As long as a user's digital device has web browsing capability, it should be able to access the collection and access must be available via multiple platforms and web browsers." (P13)

Not surprisingly, the need for ethical practices around treatment and handling of culturally sensitive indigenous resources was raised by a number of interviewees. Among them, there were a research scientist, an institutional repository administrator, a genealogist who works at a university library, and a volunteer at the community library. Their respective comments include the following:

"Also important is the treatment of cultural material within the collection. Heritage institutions have placed great importance on adding cultural material to their collections. Therefore, an indicator of social sustainability is the ratio of cultural material that is present in the collection. However, a commitment to inclusion of cultural material should also take into consideration ethical issues so that the communities to which this material belongs are not exploited. The presence of a comprehensive policy regarding the display and use of cultural materials is one indicator of how well a digital information service is treating this issue. This should be posted clearly. This indicator will ensure that content is displayed in a culturally sensitive way, that display of materials should be free of negative bias and that materials are not used without permission. A digital information service should also acknowledge the authorship and acquisition process of the materials in the collection so users are aware that specific permission has been granted for their display. Services that adhere to these indicators will aid social progress by promoting understanding of other cultures and culturally sensitive practices. The social sustainability of a collection must therefore be dependent on how well digital information services perform against these indicators." (P7)

"Inclusion of multilingual materials in the digital collection is critical for social sustainability. With the increase of minority groups in the population it is important to include content from relevant groups to increase accessibility. Additionally, the institution must take a multicultural approach to warning its users about sensitive or offensive digital documents." (P13)

"Digital collections holding indigenous knowledge traditions should recognise the importance in continuing indigenous knowledge transmission to subsequent generations, as well as providing the same knowledge to non-indigenous people respectfully." (P15)

"There is also the importance of cultural languages in their own national depositories and lack of technology to share parts of their history due to this language 
barrier. This will be a hardship for indigenous communities and minority groups that is, their language not available in these information systems for them to understand and to be used as well as share their histories on. In New Zealand, obvious example is the way Māori are very sensitive with their cultural materials, with rules and regulations in regards to who can access these materials and who cannot. Some materials have to be managed in a certain way so that no offence is taken by the Māori people and the use of their taonga or treasures." (P16)

The research scientist also commented on the importance of establishing trust, reliability and authenticity as part of any social sustainability effort. She believed this could be achieved through an honest assessment of inclusion/ exclusion of materials and being transparent about the decisions:

"The issue of reliability must also be addressed in order to build a socially sustainable collection. The authentication of materials in a digital collection creates reliability over time, so that material available for future users does not end up distorting narratives or recollections about past or current societies. Similarly, cultural heritage institutions should assess whether there are types of materials being excluded or rejected from their collections and the reasons why this exclusion is occurring. They should strive to create a collection without hidden censorship, so that freedom of information is protected and an accurate portrayal of society reaches users. That leads to trust in the collections and services too." (P7)

\section{Assessment and Evaluation}

Several interviewees talked about the importance of assessing and evaluating if and how a DCH information service is meeting its goals as an important aspect of achieving social sustainability. Equity, accessibility and usability issues were mentioned in relation to this:

"Periodic evaluations that produce actionable metrics should be conducted in order to determine how efficiently and effectively a digital collection is meeting user needs and project objectives. Institutions should be identifying how a collection or service allows people to do what they could not do before --this is a way to quantify demand, which can be used to argue for future funding. This can be extended to measure and demonstrate how that ability is contributing to social equity and social progress." (P2)

"The availability of assistive technologies is a key indicator of social sustainability. The collection needs to follow the guidelines created by the Web Accessibility Initiative to ensure those with disabilities are able to access content and should promote this. For me, flexibility of access contributes toward the social sustainability of digital collections." (P3)

An interesting point was made by one interviewee who worked part-time at a small museum, about how assessment could include examining the involvement of DCH services in efforts to improving accessibility, and the relationships and partnerships they formed with relevant organisations with regard to this: 
"At some point, it is also crucial I suppose to adhere to internally recognised accessibility guidelines and conduct user testing and evaluation. Assessment indicators could include involvement with relevant associations and institutions advocating for improvements in these areas, as well as relationships and partnerships with businesses and other organisations working in these areas." (P1)

One interviewee, a library assistant, raised an important point about relevance of a DCH information service and about involving users in assessment and evaluation:

"However, cultural heritage institutions must prepare for changing demographics and must accept that developing policies around the presumed needs of users is complex. The users themselves will be the eventual best judges of the relevance of digitised content. Responding to the information needs of users is an inexact exercise, so results from evaluation should be used by the institution to update and remodel what contents and how information is presented and supplied. Creating equitable use of digital collections and information services should start with a need assessment of the targeted user audience obtained through community consultation and other assessments." (P4)

\section{What indicators they perceive from current DCH services that suggest social sustainability}

In this section, we present the participants' responses to the question about the indicators that suggest social sustainability, based upon their experience of using current DCH services. Please see Appendix 1 with regard to this question. Participants' responses were once again manually analysed using a grounded theory approach and organized according to emerging themes. These were then collated under each of the DCH services included in this study. The responses were again categorised into three major themes and again, important themes were highlighted in bold:

1. Strategy and policy

2. Advocacy and community engagement

3. Equity, cultural sensitivity and literacy

\section{New Zealand Electronic Text Collection (http://nzetc.victoria.ac.nz)}

\section{Strategy and policy}

Embedding sustainability in strategic planning, having a clear value proposition, good organisational support and strategic promotion of the collection were perceived as positive indicators. The following are some typical comments made by the interviewees:

"The Strategic Plan which states that sustainability and a user-centred approach is to inform decision-making, planning and development, provides a solid foundation for the digital projects" 
"The resource is grounded in a clear value proposition "Various strategies are employed to market the collection, including cross-referencing content using relevant University webpages, content and system updates through the NZETC blog and Twitter, and a Wikipedia entry"

"The sustainability of NZETC lies in its significance as a collection of materials that are unique to New Zealand and the Pacific. NZETC appears to have strong organizational support and staff resources."

\section{Advocacy and community engagement}

As evidenced by the following excerpts, the interviewees also perceived efforts made to collaborate widely, to engage and involve users and the wider community as positive indicators:

"Copyright is acknowledged and for out of copyright text a Creative Commons sharealike license is used, allowing re-use of materials as long as they are linked back to NZETC. This increases social sustainability by encouraging the use and sharing of material in competitions, blogs and museum displays."

"NZETC uses Apache Cocoon and Tomcat to publish its content. Apache Cocoon is open source software that claims to be used by many sites and companies with a strong community and large number of active developers."

“The NZETC maintains professional relationships with a number of internal and external groups.

NZETC's collaborative partners include major sources of heritage and Maori resources - including Matapihi, Digital NZ and the Kiwi Research Information Service.”

\section{Equity, cultural sensitivity and literacy}

A number of interviewees discussed features they perceived to demonstrate NZETC's attempt to address equity, including accessibility of the contents, diversity in contents and support for multilingual search:

NZETC partners with federated search services including Matapihi, Digital NZ and the Kiwi Research Information Service, and texts can be downloaded in four different formats."

"The NZETC comprises a lot of New Zealand and Pacific Island texts and materials and this diversity is supported by the availability of multilingual search options."

"NZETC allows the majority of its collection to be downloaded in accessible formats. The collection provides DAISY audiobooks which can be used by the hearing impaired and XML files which can be rendered on screen readers and Braille output devices." 
"The NZETC website uses a simple design with search and browsing functions. The level of information literacy required of users to access the material is not substantial."

\section{Kete Horowhenua (http://horowhenua.kete.net.nz)}

\section{Strategy and policy}

Only one interviewee commented on the role of KH's strategic plan in facilitating social sustainability:

"KH reflects a firm commitment to social sustainability in the areas of advocacy, strategy and policy, planning, development, management and evaluation. The project development reflects the objectives of the National Digital Strategy. The project is grounded in $\mathrm{Te}$ Horowhenua Trust strategic objectives including strategic partnerships, free access to information, digital literacy, community participation and community decision-making. The project facilitates open discussion about future enhancements to the resource through the website, blog and Kete Community meetings."

\section{Advocacy and community engagement}

For $\mathrm{KH}$, it was obvious that most interviewees perceived its greatest strength to lie in the project's engagement of its users and communities:

"The entire structure of $\mathrm{KH}$ is dependent on supporting and attracting user communities for its social sustainability. There are active discussion forums within $\mathrm{KH}$, as users can create items to add to the collection which can be commented on and developed by the online community. It is clear that the users of $\mathrm{KH}$ have affection for their physical community. There are detailed exploration and corrections of minute facts and figures of the region, shared stories of their experiences and photographs to support the development of the cultural history of the region. KH clearly values user contributions to the site and from the impression made by the topics and themes of the discussion boards, it is clear KH users support the managed online space to record their memories."

"Kete Horowhenua is a user-friendly, community-driven and community-built digital library of arts, cultural and heritage resources. Content is licensed through Creative Commons Licensing. The provision of this information and knowledge has depended on collaborative relationships with a diverse range of stakeholders. Participants in the community have become empowered through their contributions, use of the site, and sharing sense of ownership of the digital library."

"Kete is setting itself up as a culturally diverse space and also encourages Maori participation and inclusion of our Maori history and heritage. Kete's main strength in terms of social sustainability is in its capacity for community involvement. It actively attempts to create user "communities" by allowing the creation of community 'baskets.'" 
One interviewee also highlighted the partnership $\mathrm{KH}$ has formed towards promoting access:

"KH connects to Digital NZ, other digital libraries that have been created using the Kete open source software (Kete Christchurch, Kete Hurunui and Kete Waimakariri) and the Horowhenua public library resources. It also has provision for advertising by local businesses on the site. This is possibly a way of increasing revenue for the community that could be used to sustain itself as part of the Horowhenua District Council's library resources. This is compatible with its partnership with the council and with SeniorNet. The provision of computers and the Internet within the local library should ensure that Kete continues to be visible to the community."

\section{Equity cultural sensitivity and literacy}

One interviewee pointed to the features available to make $\mathrm{KH}$ more accessible, while asserting the need to do more around this to ensure long-term sustainability:

"Kete does have simple measures in place in regards to accessibility, including instructions for access keys and for resizing text. Greater inclusion of assistive technologies could be put in place as the site grows to ensure sustainability into the future."

\section{New Zealand History Online (http://www.nzhistory.net.nz)}

\section{Strategy and policy}

A number of interviewees believed NZHO's contents of national and cultural values and significance were its strongest social sustainability indicators:

"The site is a rich source of authoritative historical information and an excellent platform from which to base any historical research. As the collection has been developed by professional historians, the material selected for the site is expected to have been gathered systematically, and are of high value to the intended audience, with respect to cultural value and significance."

"The NZHO website is particularly well positioned as a project from the Ministry for Culture and Heritage for economic sustainability with a strong political drive behind it, but also social sustainability with accessible content and the inherent affinity it has with national, regional and cultural identity."

\section{Advocacy and community engagement}

Again, interviewees perceived efforts made to involve and engage users and the broader community as positive indicator:

"There is an opportunity for users to comment or post on the site, using the "Community contributions" function. The process is straightforward, only an email address is needed and the content is mediated." 
"For text and specified images, NZHO uses the Creative Commons AttributionNoncommercial 3.0 New Zealand Licence, allowing copying, adaptation and distribution as long as it's attributed. I believe this promotes social sustainability by encouraging users to make active use of materials."

"Perhaps the strongest sustainable feature is that the project draws on the collections of other cultural heritage institutions for its digital content rather than simply maintaining a collection of its own."

There were a few comments on the use of social media to facilitate engagement:

"The use of social media technologies by NZHO facilitates a socially connected collection that is beneficial to users, therefore increasing its social sustainability."

"NZHO also features frequently updated social media profiles, on Twitter and Facebook which allows it to offer users something 'extra', and encourage greater use of the digital collection and information service to support its long term social sustainability."

"There is engagement with local community via social media but the site is maintained by professional historians thus may not be accepted as 'grass-roots' in its community involvement."

Interestingly, in responding to this question, there was the following response which highlighted the issue around whose 'voice' (point-of-view) was represented and presented:

"Although the collection focuses on war themes there are broader topics related to understanding New Zealand identity including some which feature a Maori perspective. However it is often unclear whose point-of-view is being provided other than an assumed 'official' one. Other cultures and communities are included within sub-themes. As a government site, it would probably take considerable effort by any group to get a 'theme' included on the site. If they did, a high level of community engagement in the process would be likely due to the high profile of the Institution and its desire to protect its reputation for representing history accurately."

\section{Equity cultural sensitivity and literacy}

Attempts for achieving equity were noted in several statements made by the interviewees:

"The site claims to adhere to the W3C standards for web accessibility."

"There is a focus on the New Zealand school curriculum and different areas are tailored to teachers and students, giving them good, accessible content at an appropriate level which is a good sign of social sustainability. There is a significant amount of Te reo Māori content, for example biographies of Māori are presented in both Māori and English. There is also a significant amount of multi-media content, including video, audio, images as well as 'interactives'. This is a good sign for social sustainability as it will attract users with different needs." 
"There is a wide variety of both indigenous and minority materials available. However this could be improved by including a Te Reo (Māori language) search option."

"The NZHO content and display is targeted to a general public level resulting in good equity of access. Most people will have sufficient digital literacy to use the site."

"The site's text content is licensed under Creative Commons Licensing. The site claims to be accessible using most browsing technologies and markets itself through promotional posters and social media channels (Facebook and Twitter). There is also an option to subscribe to an email newsletter."

\section{What they believe to be the main challenges for DCH services to main social sustainability}

In analysing the interviewees' responses to the question about challenges to social sustainability, again using a grounded theory approach, we found the responses to fall under three themes: (i) Lack of long-term strategic planning, (ii) Lack of addressing the equity issues and (iii) Lack of collaboration, community involvement and engagement.

\section{Lack of long-term strategic planning}

The following responses highlight a couple of potential risks and issues - failure to plan for social sustainability at the start of a project and lack of a sustainable funding model:

"Cultural heritage institutions that create digital collections and information services based on a 'build it, they will come' approach, and consider long-term social sustainability only at the end of a project risk misalignment with user needs and objectives, and undermining the resources invested." (P2)

"Kete Horowhenua solicits and depends on donations from the public to put plans into action as well as to maintain the current phase of the site. This may not be sustainable unless there is a more formal structure to it." (P4)

"KH received project funding from Digital NZ and is supported by the local District Council. There is an element of risk to KH funding which may adversely impact on its sustainability. However if the project can show high value collections and if they have sufficient community value, they may be supported by larger economically sustainable institutions." (P8)

\section{Equity Issues}

Lack of equity around accessibility, usability, diversity of language representation and relevant contents, and lack of cultural sensitivity were highlighted:

"The NZETC display interface is quite basic and easy to follow, but feels staid and is likely too academic for some. The site is unlikely to appeal to a younger audience. “(P3) 
While the Ministry for Culture and Heritage's website is available in Te Reo Maori, NZHO is only viewable in English. Unlike NZETC, searching is only possible in English. This is a potential issue, given its ministerial ties. There is no help section on NZHO, representing a problem as users that encounter trouble have no hope of assistance. (P6)

NZHO only includes a brief accessibility section that explains how alt shortcuts can be used by those with mobility issues to browse the collection. If other accessibility features are present on the site, they are not immediately obvious. (P7)

Despite its focus on New Zealand and Pacific Island materials, the NZTEC is only available in English. Additionally, it does not warn for potentially offensive content. Similarly, NZHO does not provide information as to whether documents of cultural or political sensitivity are included in the collection. (P16)

\section{Lack of Collaboration, Community involvement and engagement}

The lack of evidence of community engagement and involvement were perceived by some as barriers to achieving social sustainability. So was the lack of collaboration and operating on a small scale:

'NZETC doesn't support the integration of users' knowledge with the collection, and adding more interactive and participatory functionality could potentially further support research.” (P2)

"There needs to be (for NZETC) a better visibility with digital content through community engagement. Otherwise, it may lose the connection with communities that can benefit from it." (P10)

"With NZETC, it should link the collection to a larger collaborative initiative and catering to users who do not use one collection exclusively. "(P13)

"KH aims to construct a vibrant community of users who add value to the site on a voluntary or reciprocal basis. This can be seen as a strength. However, operating on too small a scale, on its own can be a threat to the social sustainability." (P15)

\section{Discussion of the Main Findings}

Analysis of interview results leads to four main themes, under which the issues raised and identified by study participants as important for the social sustainability of DCH services could be organised.

\section{Strategy and policy}

The perceived benefits of having relevant strategies and policies in place were linked to sending a clear message about an institution's stance on social sustainability, as well as to meeting current and future needs of users and communities. This was also perceived to be important to guide resource allocation and risk management, which can be particularly important in dealing with resources of cultural significance and political sensitivity. Two 
participants also emphasised the importance of addressing this not only at an institutional level, but in a wider context, taking into consideration for instance, of sector-wide concerns and the appropriate legal framework.

\section{Advocacy and community engagement}

Advocacy, and the building and maintaining of relationships with users and the wider community, are perceived by a number of interviewees to be important steps towards social sustainability. Empowering users and providing them a sense of ownership was perceived to be an important aspect of managing digital cultural heritage project engagement. The issue of cultural diversities was raised, emphasising the importance of ensuring equity of representation of the different cultures of the communities the DCH serves. It was suggested that any DCH should be built around the community, taking into account the identity, social structures and work practices of the communities concerned. Consultation and engagement with the communities concerned were also mentioned as key steps towards achieving social sustainability, as was the importance of developing trust, a sense of identity and ownership and encouraging collaboration and participation among users and the wider communities.

\section{Inclusivity, cultural sensitivity and literacy}

The importance of equity was raised by most of the interviewees. Most of them commented on the need to represent the diversity of cultures, languages and literacy skills. Accessibility and usability were also perceived to be important concerns. A number of participants linked equity of access to technology compatibility. Not surprisingly, the need for ethical practices around treatment and handling of culturally sensitive indigenous resources were raised by a number of interviewees. One interviewee also made the point about embedding socially sustainable practice in organisational culture and how this should provide a foundation for policy formulation. The importance of establishing trust, reliability and authenticity as part of any social sustainability effort was mentioned, and an example was provided on how this could be achieved through an honest assessment of inclusion / exclusion of materials and being transparent about these decisions.

\section{Assessment and evaluation}

The importance of assessing and evaluating if and how a DCH information service is meeting its goals, as an important aspect of achieving social sustainability, was raised by a number of interviewees. Equity, accessibility and usability issues were mentioned in relation to this. Interesting points were made about involvement of users in assessment and evaluation, and about how assessment could include examining the efforts made by $\mathrm{DCH}$ to improve and manage the relationships and partnerships they formed with relevant organisations.

\section{Conclusions}

Overall, it was noted that all the three chosen DCH information services meet a number of the social sustainability criteria identified in the previous section. However, there are some differences among the three DCH information services because of their nature and content, as well as the organization that owns each one, and provides the service. For example, NZTEC is a university DCH information service as opposed to NZHO which is a service from the 
government ministry, and $\mathrm{KH}$ which is a community-built service. It is good to note that each service clearly states their overall strategy and policy and they are available to members of general public through easy open access tools. However, there are certain differences, as well. For example, $\mathrm{KH}$ is built by members of the community who want to share their information with others, while the NZHO collection is built by professional historians.

All the services use the appropriate web 2.0 and social media technologies in order to engage with the communities. Some however, make more use of crowdsourcing technologies to build and annotate the collections. $\mathrm{KH}$ is a prominent example of this type of community engagement for building and sharing its collection. It also makes provisions for advertisement of local businesses, thereby drawing on more local community resources. Other services use a different kind of community engagement, for example, NZHO draws on the collections of other cultural heritage institutions for its digital content rather than simply maintaining a collection of its own.

Although the social sustainability attributes identified in this study have been categorised under four themes, they are often inter-related. The next phase of the study would aim to validate and extend if necessary, the list of social sustainability attributes in a larger sample of DCH information services. This will help us move towards a validated model for the social sustainability attributes for DCH information services. It will also be interesting to study if and in what ways each social sustainability attribute have impact on one another and thus how attributes can be optimised in order to build socially sustainable DCH information services.

\section{References}

Adelle, C. and Pallemaerts, M. (2009). Sustainable development indicators: an overview of relevant Framework Programme funded research and identification of further needs in view of EU and international activities. European Commission, Seventh Framework Programme. Retrieved from: http://www.ieep.eu/assets/443/sdi_review.pdf

Cane, P. and Conagham, J. (2009). The new oxford companion to law. Oxford University Press.

Chowdhury, G. G. (2015). Cultural heritage information services: sustainability issues. In: Ruthven, I. and Chowdhury, G.G. (eds). Cultural Heritage Information: Access and Management. iResearch Series, London, Facet Publishing, 221-45.

Chowdhury, G.G. (2014). Sustainability of Scholarly Information. London, Facet Publishing.

Chowdhury, G.G. (2013). Sustainability of digital information services. Journal of Documentation, 69(5), 602-622.

Deodato, J. (2014). The patron as producer: libraries, web 2.0, and participatory culture, Journal of Documentation, 70(5), $734-758$.

European Commission. (2014). Culture: Supporting Europe's Cultural and Creative Sectors. Retrieved from http://ec.europa.eu/culture/policy/culture-policies/cultural-heritage_en.htm

Feather, J. (2013). The information society: a study of continuity and change. $6^{\text {th }}$ Ed. London, Facet Publishing.

Francis, K.D. and Liew, C. L. (2009). Digitised indigenous knowledge in cultural heritage organisations in Australia and New Zealand: an examination of policy and protocols. 
Proceedings of the American Society for Information Science and Technology, 46(1), 1-21. Retrieved from: https://www.asis.org/Conferences/AM09/open-proceedings/papers/5.html

Hutchins, M.J., Gierke, J.S. and Sutherland, J.W. (2009). Decision making for social sustainability: a lifecycle assessment approach. IEEE International Symposium on Technology and Society, 2009. ISTAS ‘ $09,1-5$.

Hutchins, M. and Sutherland, J.W. (2008). An exploration of measures of social sustainability and their application to supply chain decisions. Journal of Cleaner Production, 16(15), 1688-1698.

Innocenti, P. (2015). Cultural Networks in Migrating Heritage: Intersecting Theories and Practices across Europe. Ashgate.

Liew, C. L. (2014). Participatory cultural heritage: a tale of two institutions' use of social media. $D$ Lib Magazine, 20(3/4). _Retrieved from: http://www.dlib.org/dlib/march14/liew/03liew.html

Liew, C. L. (2012). Towards Socially Inclusive Digital Libraries. In Digital Libraries and Information Access: Research Perspectives, edited by Chowdhury, G. G. and Foo, S. Facet Publishing: 97-111.

Liew, C. L. (2010). Digital Libraries for Cultural Heritage. In Business Planning for Digital Libraries: International Approaches, edited by Collier, M. Leuven University Press: 195-205.

Mak, M. Y and Peacock, C. J. (2011). Social sustainability: a comparison of case studies in UK, USA and Australia. 17th Pacific Rim Real Estate Society Conference, Gold Coast, 16-19 Jan 2011. Retrieved from: www.prres.net/papers/Mak_Peacock_Social_Sustainability.pdf

Nakata, M., Nakata, V., Gardiner, G., McKeough , J. Byrne, A. and Gibson, J. (2008). Indigenous Digital Collections: An Early Look at the Organisation and Culture Interface, Australian Academic \& Research Libraries, 39(4), 223-236.

Nicholas, D., Clark, D., Rowlands, I. and Jamali, H.R. (2013). Information on the go: a case study of Europeana mobile users. Journal of the American Society for Information Science and Technology, 64(7), 1311-1322.

Tait, E., MacLeod, M. , Beel, D., Wallace, C., Mellish, C. and Taylor, S. (2013). Linking to the past: an analysis of community digital heritage initiatives, Aslib Proceedings: New Information Perspectives, 65(6), $564-580$.

UNESCO. (2008). UNESCO World Heritage Information Kit. Retrieved from http://whc.unesco.org/ uploads/activities/documents/activity-567-1.pdf 


\section{Appendix 1 Pre-Interview Questionnaire}

The following 'questionnaire' was emailed to each participant in preparation for the interviews two weeks prior.

\section{Survey Regarding Social Sustainability of Digital Cultural Heritage (DCH) Projects}

Thank you for your consent to participate in this study. In preparation for the upcoming interview, it would be helpful if you could take a look at the two broad questions that would be used to guide the semi-structured interview:

- What factors do you consider are important for DCH projects to be socially sustainable or to achieve social sustainability?

- What do you believe are the main challenges for DCH projects to achieve or maintain social sustainability?

You may find the following references on social sustainability useful for your preparation:

- Baehler, K. (2007). Social Sustainability: New Zealand's Solution to Tocqueville's Problem. Social Policy Journal of Aotearoa/New Zealand, 31, pp. 22-40. https://www.msd.govt.nz/documents/aboutmsd-and-our-work/publications-resources/journals-and-magazines/social-policy-journal/spj31/31Pages22-40.pdf

- Magee, L., Scerri, A. and James, P. (2012). Measuring Social Sustainability: A Community-Centred Approach. Applied Research Quality Life, 7, pp. 239-261. https://www.academia.edu/5178539/ Measuring Social Sustainability A Community-Centred Approach

- Omann, I. and Spangenberg, J.H. (2002). Assessing Social Sustainability: The Social Dimension of Sustainability in a Socio-Economic Scenario. Paper presented at 7th Biennial Conference of the International Society for Ecological Economics. http://seri.at/wp-content/uploads/2010/05/ Assessing_social_sustainability.pdf

Also, we would appreciate your responses to the following questions.

Please either (i) email your responses to ChernLi.Liew@vuw.ac.nz prior to the interview OR (ii) bring along your responses to the face-to-face interview.

\section{Your Background}

Gender: Age:

Current employment:

Have you used the following DCH(s)?

- New Zealand Electronic Text Collection (http://nzetc.victoria.ac.nz)

If yes, please state the Purpose(s) of use:

- Kete Horowhenua (http://horowhenua.kete.net.nz)

If yes, please state the Purpose(s) of use:

- New Zealand History Online (http://www.nzhistory.net.nz)

If yes, please state the Purpose(s) of use:

For each of the DCH(s) you've used, we would appreciate your answers to the following question.

- What indicators do you perceive from the current DCH project(s) that suggest social sustainability?

The more specific the information you provide us with, the more useful this study will be. Thank you for your time and effort in advance.

Please note that your identity and responses will be kept confidential. There will be no attribution of data that will identify you in the reporting of the study findings. 


\section{Appendix 2}

\section{Interview data extracts on the 'Equity, Cultural sensitivity and Literacy' theme}

\section{Cultures, Languages and Literacy skills}

"Complexity and sensitivity are critical in developing culturally sensitive digital collections for multicultural users. Post-colonial tension and political correctness need to be considered carefully. In the New Zealand context, Treaty of Waitangi obligations must be implemented regarding content and language. Does the digital collection reflect the cultural diversity of the topic, the society and the archive itself? A measure of the number of in and out links to diverse, authoritative resources that user groups know and trust can indicate effort to build cultural bridges. A vital way to avoid problems is to have a programme of community consultation, community engagement and empowerment. This should be in regard to the collection design as well as content”. (P3)

"Technology literacy needs to be regarded carefully. Is the collection designed in a manner that is easy to access for those not highly computer-literate? Are their options for more advanced users and for users to personalise as they progress in use experience? Support for bilingual or multilingual interfaces is also a crucial aspect. As a minimum, the interface should be available in all official languages of the host country. If significant content or end-users use a particular language, this language should be catered for." (P3)

"There are many roles that cultural heritage institutions can play in managing socially sustainable digital collections and information services. These roles relate to the issue of fair access to content, the issue of user literacy and language, the issue of fair treatment of cultures and cultural material and the issue of reliability of information." (P7)

"Cultural institutions must also address the issue of user literacy and language. Basically, if a digital collection cannot be understood by its users, it will not be used. Therefore, the proportion of user friendly features available for browsing the collection should always be considered and assessed. The collection must cater for multilingual communities if it wishes to be socially sustainable. The percentage of site features offered in non-English and the percentage of items in the collection that are in non-English and minority languages are both indicators that can be used to determine how fair the collection is to all members of society." (P7)

\section{Accessibility and Usability}

"Having measures in place to ensure the widest range of people possible have access to content is one way to ensure the digital collection stays relevant into the future. The digital cultural site must also have measures in place to make it accessible to all groups, including those with vision and hearing impairments and learning disabilities. Especially relevant in New Zealand is offer support for bilingual or multilingual interfaces. One final consideration is that of information literacy. Not everyone that uses the digital library may be proficient in the use of information technology, therefore options for using and contributing must be simple and straightforward. It must also be accessible to people with nonbroadband Internet access." (P9)

"Social sustainability relates to human needs, needs of society and has a focus on the future. Improved social equity and social progress should be the goals of a socially sustainable digital information services. Support for multilingual interfaces is important to New Zealand. It should be expected that contents in 'non-principal' languages be translated, with the option for subtitled videos and transcripts of audio materials. These are keys to supporting a diverse user base. Engaging and reacting to user needs are indicators of social sustainability and this outreach should occur before and after launch.” (P6)

"It is important to ensure technologies are implemented in a way to suit targeted users. Consideration needs to be on including all elements to ensure cultural heritage collections can be accessible by all communities that results in effective trust." (P10)

"The collection interface should not be unnecessarily complex, nor should the collection require a high degree of information or digital literacy to negotiate. Navigation should be intuitive and easy to master. There should be a help function to allow users to learn how to search the collection and make the most of its resources. If funds permit it, a guided tour function will also assist user learning. The collection's interface should be able to be used by the elderly and the visually impaired." (P13) 
"When a collection is selected for digitalisation, often a community or user group is privileged and whose values are embedded in institutional aims and selection policies. To achieve social sustainability, minority histories and knowledge must be represented. Widening access to digital collections creates new ways of building social cohesion and identity. Greater collaboration may result in improved knowledge sharing and building identity. However, minority groups may mistrust institutions and be reluctant to collaborate because of the lack of involvement and consultation which I understand is not uncommon." (P8)

"Digital collections that contain socially and culturally diverse content may be able to keep up social change that is driven by desire for equality. An indication of this may be a goal or mission statement on the website. Cultural institutions must accept that complexity exists within society and be aware of and sensitive to all relevant cultural issues, taboo and cultural imperatives in the design, creation and maintenance of the site. Evidence of this may be design and content that embraces a culture or many cultures and features that elicit and encourage contribution and feedback. They may also empower users by including them as contributors of contents. That should also cultivate commitment and a sense of ownership.” (P9)

"A digital collection needs to meet the compatibility of users and create social awareness. Some users are excluded from technology access because of their IT literacy, previous experience, age, gender or disability and cultural heritage material can be overwhelming for users who do not know how to find and interpret information. It means sufficient support towards creating a collection that meets community needs should be considered for diverse information needs Empowering communities to create effective mechanisms will help assist in sustaining a collection that is targeted for them and their technological backgrounds." (P10)

"Language is the primary form of access to a culture and this has been demonstrably true of Te reo Māori. Social sustainability in this context would mean that digital heritage project would factor in a multilingual approach with particular attention to Te reo Māori, one of the three official languages of New Zealand." (P11)

"There must be no bias as to which cultures are represented in the collection. Digitisation projects often put more emphasis on digitizing the content rather than providing for the needs of the community." (P14)
"The importance of recognising different users' behaviours and needs extends beyond conventional information sources and into memory institutions' digital collections which must be tailored just as much, if not more than conventional print collections to ensure community engagement is achieved. Suitable methods of communication are also key to developing a sense of shared identity with users. This is particularly important in parts of the population who have limited or impaired information and technology literacy." (P13)

"An important issue for social sustainability is whether a collection can play a role in widening access to information related to national identity, especially information about socially diverse groups, minority cultures and their knowledge practices. Not all users have the same computer skills, educational background, have English as their first language, or can use advanced searches, fields and filtering. Creating an easy or familiar formatted user interface such as a Google-like search tool to search a digital collection is an example assessment factor in whether a digital library's collection is too complicated for the basic user." (P15)

"Access is vital in this process of sustainability. Sustaining cultural heritage collections through digital means requires education on how to access them. Other issues include technology obsolescence. Forms of technology sometimes become extinct and not in use with the new or current technologies out there resulting in information held on them not able to be shown. Also important for heritage organisations is to include what the users want not only the present but for the future as well to ensure the use of their collections and ensure the importance of what the organisation exists for." (P16)

"Firstly, access to digital developments should not be expensive. While these projects are often costly to implement and maintain, care must be taken to ensure that information is not being denied to those who cannot afford any fees associated with the collection. This is especially important when the intellectual and/ or cultural owners of digital resources in the collection wish to access these items." (P13)

"The interface for the collection needs to be set up to cater for a diverse range of individuals. Indicators for a sustainable system interface include ease of learning, ease of usage and adaptability. The system interface needs to be available for use in a variety of devices such as laptops, mobile phones and tablets." (P14) 